\title{
Antagonism by hemoglobin of effects induced by L-arginine in neuromuscular preparations from rats
}

C.R. Ambiel ${ }^{2}$ and Wilson Alves-Do-Prado ${ }^{1}$

\author{
Departamentos de ${ }^{1}$ Farmácia e Farmacologia and ${ }^{2}$ Fisiologia,
} Universidade Estadual de Maringá, M aringá, PR, Brasil

\section{Correspondence \\ W. Alves-Do-Prado \\ Laboratório de Farmacologia da \\ Transmissão Neuromuscular \\ DFF, UEM \\ Av. Colombo, 5790 \\ 87020-900 M aringá, PR \\ Brasil \\ Fax: + 55-44-225-3863 \\ E-mail: alvesprado@wnet.com.bror \\ waprado@dff.uem.br \\ Research supported by $\mathrm{CNPq}$ \\ (No. 521727/96).}

Received April 12, 2000

Accepted January 30, 2001

\section{Abstract}

Nitric oxide (NO)-synthase is present in diaphragm, phrenic nerve and vascular smooth muscle. It has been shown that the NO precursor Larginine (L-Arg) at the presynaptic level increases the amplitude of muscular contraction (AMC) and induces tetanic fade when the muscle is indirectly stimulated at low and high frequencies, respectively. However, the precursor in muscle reduces AMC and maximal tetanic fade when the preparations are stimulated directly. In the present study the importance of NO synthesized in different tissues for the L-Arg-induced neuromuscular effects was investigated. Hemoglobin $(50 \mathrm{nM})$ did not produce any neuromuscular effect, but antagonized the increase in AMC and tetanic fade induced by L-Arg (9.4 $\mathrm{mM})$ in rat phrenic nerve-diaphragm preparations. D-Arg $(9.4 \mathrm{mM})$ did not produce any effect when preparations were stimulated indirectly at low or high frequency. Hemoglobin did not inhibit the decrease of AMC or the reduction in maximal tetanic tension induced by L-Arg in preparations previously paralyzed with d-tubocurarine and directly stimulated. Since only the presynaptic effects induced by L-Arg were antagonized by hemoglobin, the present results suggest that NO synthesized in muscle acts on nerve and skeletal muscle. Nevertheless, NO produced in nerve and vascular smooth muscle does not seem to act on skeletal muscle.

Nitric oxide (NO) is generated from Larginine by NO-synthase (1-3). Neuronal NOsynthase is present in the sarcolemma of type II skeletal muscle fibers (4) and in the motor nerve of rats (5). It has been shown that the addition of the NO precursor L-arginine (4.7$9.4 \mathrm{mM}$ ) to rat neuromuscular preparations increases the amplitude of muscular contraction (AMC) in preparations indirectly stimulated at $0.2 \mathrm{~Hz}(6)$. In contrast, L-arginine
(4.7-9.4 $\mathrm{mM}$ ) reduces AMC when preparations previously paralyzed with d-tubocurarine are directly stimulated at low frequency (7). The facilitatory and inhibitory effects of L-arginine depend on its metabolism to NO, with actions at the pre- and postsynaptic level, respectively (7). Studies conducted at high frequencies of stimulation applied to the motor nerve have shown that L-arginine (4.7-18.4 $\mathrm{mM}$ ) produces a dose- 
dependent tetanic fade followed by reduction in maximal tetanic tension (6). The tetanic fade and the reduction in maximal tetanic tension induced by L-arginine are produced by the action of NO on the motor nerve and skeletal muscle, respectively (6). The presynaptic effects observed with Larginine reach their maximum at concentrations around $9.4 \mathrm{mM}(6,7)$.

Hemoglobin may cross the wall of a large vein (8), but its diffusion through the membranes of other tissues is negligible (9). NO (authentic gas) disappears rapidly when hemoglobin is added to the bath (10), at a rate proportional to hemoglobin concentration in the bath (10). Since hemoglobin only scavenges NO released from tissues, the pre- and postsynaptic neuromuscular effects induced by NO released from skeletal muscle, motor nerve and/or vascular smooth muscle might be reduced or antagonized by previous administration of the scavenger. Therefore, the present study with hemoglobin was undertaken to determine the relative importance of NO produced from skeletal muscle, nerve and vascular smooth muscle for the neuromuscular effects induced by L-arginine.

Phrenic nerve and diaphragm muscle were isolated from Wistar rats (200-250 g) of both sexes and mounted according to the method described by Bülbring (11). Each muscle was immersed in a 30-ml chamber containing Krebs buffer. The phrenic nerve was stimulated with a bipolar platinum electrode using a supramaximal rectangular pulse $(0.2$ $\mathrm{Hz}, 0.05 \mathrm{~ms}$ ) and muscle contractions were recorded on an Ugo Basile polygraph.

In studies performed at a low frequency of stimulation, the isolated muscles were stimulated at $0.2 \mathrm{~Hz}$ until a steady AMC was obtained. L-Arginine $(9.4 \mathrm{mM})$ was then added to the organ bath and the AMC obtained after 20 min was taken as a percentage of that observed before any drug administration. In the experiments performed with a high frequency of stimulation applied to the motor nerve, the standard rate of stimulation was $0.2 \mathrm{~Hz}$. Nevertheless, stimulation at a higher (tetanic) rate was applied to the nerve for $10 \mathrm{~s}$ at 20 -min intervals. The same experimental design was used for neuromuscular preparations previously paralyzed with $d$ tubocurarine and directly stimulated. The tension produced at the beginning of tetanic stimulation (A) was compared to that obtained at the end of tetanic stimulation (B). The stimulation rate $(\mathrm{F})(180-200 \mathrm{~Hz})$ required to obtain a 0.50 ratio $(\mathrm{R}=\mathrm{B} / \mathrm{A})$ was determined for each preparation and used throughout the experiments. L-Arginine or D-arginine was then added to the organ bath and $\mathrm{F}$ was repeated at $\mathrm{t}=20,40,60$ and 80 $\min$. Krebs buffer in the bath was replaced with drug-free Krebs buffer (4 times) at $\mathrm{t}=$ $90 \mathrm{~min}$ and the $\mathrm{R}$ ratio was observed at $\mathrm{t}=$ 100 and $120 \mathrm{~min}$. The same sequences were repeated with the use of hemoglobin, except that the NO-scavenger was added $5 \mathrm{~min}$ before $\mathrm{L}$-arginine. The $\mathrm{R}$ ratio obtained after drug addition was taken as a percentage of that observed before drug administration. Data were submitted to ANOVA, followed by the Bonferroni test, with the level of significance set at $\mathrm{P}<0.05$. The following drugs were used: L-arginine, D-arginine and bovine hemoglobin (Sigma Chemical Co., St. Louis, MO, USA).

Confirming previous reports with L-arginine, our study showed that L-arginine (9.4 $\mathrm{mM}$ ) increased AMC induced by low frequency of stimulation and produced tetanic fade when high frequencies $(180-200 \mathrm{~Hz})$ of stimulation were applied to the motor nerve (Figures 1 and 2). L-Arginine also reduced AMC $(30 \pm 0.02 \%, \mathrm{~N}=8)$ and maximal tetanic tension $(50 \pm 0.04 \%, \mathrm{~N}=6)$ in neuromuscular preparations previously paralyzed with d-tubocurarine and directly stimulated. The effects observed with L-arginine were stereospecific, since D-arginine (data not shown) was not effective in similar experiments. Results resemble those obtained in other studies using similar preparations and methods $(6,7)$ and depend on the action of 
$\mathrm{NO}$ at the presynaptic (increase in AMC and tetanic fade) and postsynaptic (reduction in AMC and maximal tetanic tension) levels $(6,7)$.

Hemoglobin did not produce any effect on AMC or on tetanic fade of preparations indirectly stimulated with pulses at low or high frequency, respectively. However, hemoglobin induced a dose-dependent (25-50 $\mathrm{nM})$ reduction in the facilitatory effect induced by L-arginine when the nerve was indirectly stimulated at low frequency (Figure 1). It was also verified that 50 and 100 $\mathrm{nM}$ hemoglobin antagonized the tetanic fade induced by $9.4 \mathrm{mM}$ L-arginine (Figure 2). On the other hand, hemoglobin neither inhibited nor reduced the postsynaptic effects induced by NO in preparations previously paralyzed with d-tubocurarine and directly stimulated. Taken as a whole, the results showed that hemoglobin only antagonized the NO-induced presynaptic effects. This suggests that $\mathrm{NO}$ synthesized in muscle may act on nerve and in muscle, whereas NO produced in nerve and vascular smooth muscle seems to act solely at the presynaptic level.

\section{Acknowledgments}

We are grateful to Mrs. I.L. Santos for technical support. We also thank Prof. Dr. F. Cunha for kindly supplying bovine hemoglobin.

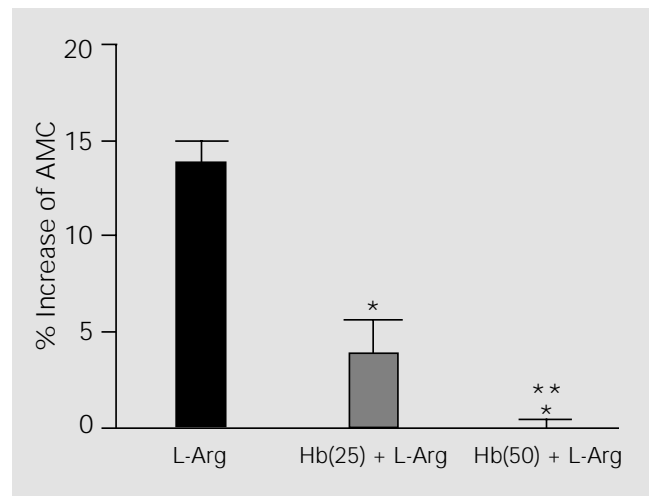

Figure 1 - Percent increase of amplitude of muscular contraction (AMC) induced by L-arginine (L-Arg, $9.4 \mathrm{mM}$ ) in the absence or presence of 25 and $50 \mathrm{nM}$ hemoglobin $(\mathrm{Hb})$ in neuromuscular preparations indirectly stimulated at $0.2 \mathrm{~Hz}$. The height of the column represents mean $( \pm$ SEM) of 5 to 6 experiments. $* \mathrm{P}<0.05$ compared to control (ANOVA). $* * \mathrm{P}<0.05$ compared to $25 \mathrm{nM} \mathrm{Hb}$ (Bonferroni post hoc test).

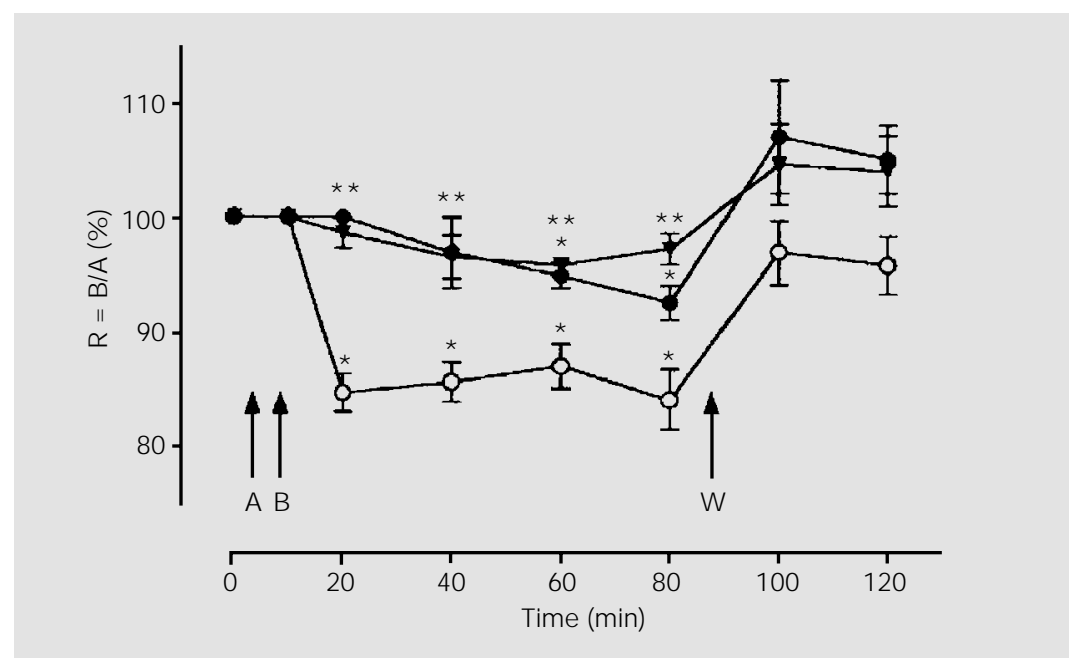

Figure 2 - Percent reduction of $R$ values induced by L-arginine $(9.4 \mathrm{mM})$ in the absence (open circles) or presence of $50 \mathrm{nM}$ (filled circles) and $100 \mathrm{nM}$ (filled triangles) hemoglobin in indirectly stimulated neuromuscular preparations. On the ordinate, the $\mathrm{R}$ ratio is expressed as a percentage of that obtained for drug-free Krebs buffer, taken as $100 \%(t=0)$. The abscissa represents time. A and B represent the times of hemoglobin and L-arginine addition, respectively. W indicates replaced drug-free Krebs buffer (4 times). Points represent mean $( \pm$ SEM) of 6 to 7 experiments. $* \mathrm{P}<0.05$ compared to control (ANOVA) $* * \mathrm{P}<0.05$ compared to L-arginine in the absence of hemoglobin (Bonferroni post hoc test).

\section{References}

1. Mayer B, Schmidt K, Humbert P \& Bohme E (1989). Biosynthesis of endotheliumderived relaxing factor: a cytosolic enzyme in porcine aortic endothelial cells $\mathrm{Ca}^{2+}$ dependently converts L-arginine into an activator of soluble guanylyl cyclase. Biochemical and Biophysical Research Communications, 164: 678-685.

2. Pollock J S, Förstermann U, Mitchell JÁ, Warner TD, Schmidt HHHW, Nakane M \& Murad F (1991). Purification and charac- terization of particular endothelium-derived relaxing factor synthase from cultured and native bovine aortic endothelial cells. Proceedings of the National Academy of Sciences, USA, 88: 10480-10484.

3. Schmidt HHHW, Pollock J S, Nakane M, Förstermann U \& Murad F (1992). $\mathrm{Ca}^{2+}$ calmodulin-regulated nitric oxide synthases. Cell Calcium, 13: 427-434.

4. Kobzik L, Reed MB, Bredt DS \& Stamler J S (1994). Nitric oxide in skeletal muscle.
Nature, 372: 546-548.

5. Ribera J, Marsal J, Casanovas A, Hukkanen M, Tarabal O \& Esquerda J E (1998). Nitric oxide synthase in rat neuromuscular junctions and in nerve terminals of Torpedo electric organ: its role as regulator of acetylcholine release. J ournal of Neuroscience Research, 51: 90-102.

6. Silva HMV, Ambiel CR \& Alves-Do-Prado W (1999). The neuromuscular transmission fade (Wedensky inhibition) induced 
by L-arginine in neuromuscular preparations from rats. General Pharmacology, 32: 705-712.

7. Ambiel CR \& Alves-Do-Prado W (1997). Neuromuscular facilitation and blockade induced by L-arginine and nitric oxide in the rat isolated diaphragm. General Pharmacology, 28: 789-794.

8. Skopp G, Potsch L, Lutz R, Ganssmann B
\& Mattern R (1998). Hemoglobin diffusion across a venous wall: an experimental study. American J ournal of Forensic Medicine and Pathology, 19: 372-376.

9. Vaughn MW, Huang KT, Kuo L \& Liano J C (2000). Erythrocytes possess an intrinsic barrier to nitric oxide consumption. J ournal of Biological Chemistry, 275: 23422348.
10. Hakim TS, Sugimori K, Camporesi EM \& Anderson G (1996). Half-life of nitric oxide in aqueous solutions with and without haemoglobin. Physiological Measurement, 17: 267-277.

11. Bülbring $E$ (1946). Observations on the isolated phrenic nerve diaphragm preparation of the rat. British J ournal of Pharmacology, 1: 38-61. 